\title{
A case of recurrent hypoglycemia in pregnancy
}

\section{Padmanabhan Vijayaraghavan}

Department of Medicine, Madras Medical College and Rajiv Gandhi

Government General Hospital, Chennai, Tamil Nadu, India

Address for the Correspondence: Dr. Padmanabhan Vijayaraghavan,

1-B, Karpaga Vijayam, No. 1, Subramaniam Street, Abhiramapuram, Chennai - 600018 ,

Tamil Nadu, India.

E-mail: drvpmd@gmail.com

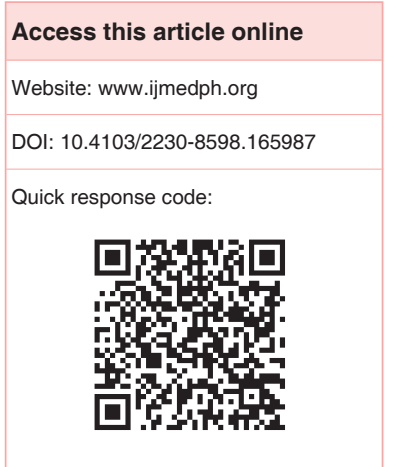

A 33-year-old female who was 34 weeks into her third pregnancy with no previous medical illness developed giddiness and loss of consciousness and was hospitalized. Her capillary blood glucose was found to be $20 \mathrm{mg} \%$. She fully regained her consciousness after $25 \%$ dextrose infusion. Over the next $24 \mathrm{~h}$, she developed three more episodes and was similarly treated. After the fourth episode, she deteriorated and in spite of supportive measures expired $<36 \mathrm{~h}$ after the onset of the illness. Laboratory results showed raised serum creatinine and total leukocyte count (TLC); her abdominal ultrasonogram showed Grade 1 medical renal disease. A routine glucose tolerance test carried out in the $24^{\text {th }}$ week of pregnancy had showed a hypoglycemic tendency. The combination of raised TLC, suggesting an acute bacterial infection, together with the underlying silent chronic kidney disease probably resulted in severe and recurrent hypoglycemia. This case underlines the need to do serum creatinine as part of a routine antenatal check-up.

Key words: Antenatal check-up, chronic kidney disease, hypoglycemia, insulin sensitivity, pregnancy, sepsis

\section{INTRODUCTION}

A 33-year-old female who was 34 weeks into her third pregnancy with no previous medical illness, presented with severe hypoglycemia that turned out to be fatal. Investigations revealed evidence for chronic kidney disease (CKD) and evidence of an acute bacterial infection. The combination of $\mathrm{CKD}$ and acute bacterial infection causing recurrent hypoglycemia in an antenatal mother has not been reported so far.

\section{CASE REPORT}

A 33-year-old female developed tiredness, giddiness, and loss of consciousness (LOC) at her residence around 10.30 p.m. on September 14, 2014. She was 34 weeks pregnant (last menstrual period-January 23, 2014, gravida-3/para-1/alive-1). An ambulance was called, and she was shifted to a tertiary hospital. In the emergency room, her capillary blood glucose (CBG) was found to be $20 \mathrm{mg} \%$. After $25 \%$ dextrose was infused, she recovered, became conscious and oriented and was admitted as an in-patient at $1.50 \mathrm{a} . \mathrm{m}$. on September 15, 2014. Physical examination at that time revealed the presence of fetal heart sounds.

Around 8 a.m., she developed giddiness and LOC again. Her CBG was found to be low. $25 \%$ dextrose was infused again, and she recovered. Though maintained on dextrose containing fluids she developed a third and a fourth episode of LOC and was similarly treated with $25 \%$ dextrose. After the fourth episode, she did not recover fully and since her Glasgow coma scale score was 8/15, she was intubated at 2 p.m. She went into cardiac arrest at 8.20 p.m. and was revived and maintained on life support. On September 16, 2014, at 9.05 a.m. she expired.

This is an open access article distributed under the terms of the Creative Commons AttributionNonCommercial-ShareAlike 3.0 License, which allows others to remix, tweak, and build upon the work non-commercially, as long as the author is credited and the new creations are licensed under the identical terms.

For reprints contact: reprints@medknow.com

How to cite this article: Vijayaraghavan P. A case of recurrent hypoglycemia in pregnancy. Int J Med Public Health 2015;5:391-2. 
Investigations showed - hemoglobin: $10 \mathrm{~g} \%$, blood urea-98, serum creatinine-3.8, Na-126, K-4.7, total leucocyte count (TLC)-32,000, polymorphs-82/lymphocytes-13/eosinophils-5. Ultrasonogram (USG) abdomen showed-normal sized kidneys with Grade 1 medical renal disease and single uterine gestation with intrauterine death. She was a booked case in a local health center. There was no history of diabetes mellitus, other medical ailments, fever, or similar episodes in the past. Report of oral glucose tolerance test (GTT) done on July 12, 2014 (in her $24^{\text {th }}$ week of pregnancy) in a private lab showed:

\begin{tabular}{lcccc}
\hline FBS & $\mathbf{1} \mathbf{2} \mathbf{h}$ & $\mathbf{1} \mathbf{h}$ & $\mathbf{1} \frac{1}{\mathbf{2}} \mathbf{h}$ & $\mathbf{2} \mathbf{h}$ \\
\hline 52 & 91 & 105 & 102 & 98 \\
\hline
\end{tabular}

FBS: Fasting blood sugar

The hypoglycemic tendency is noted in the GTT, the significance of which was apparently unrecognized at that time. The tendency for increased insulin sensitivity is known to occur in CKD. Raised creatinine and USG finding of Grade 1 medical renal disease (MRD) are suggestive of underlying CKD.

Two conditions can be thought of causing severe recurrent hypoglycemia in this case:

1. Undiscovered CKD with increased insulin sensitivity.

2. Sepsis, known to cause hypoglycemia, is suggested by the TLC of 32,000 with predominant polymorphs, but there is no history of fever.

\section{DISCUSSION}

During normal pregnancy, there is an increase in the size of the kidneys up to $1.5 \mathrm{~cm}$. Normal sized kidneys during pregnancy are in favor of CKD. In CKD, there is increased insulin sensitivity because of decreased clearance of insulin. ${ }^{[1,2]}$ In addition, there is decreased gluconeogenesis in kidneys due to CKD. Sepsis is known to cause hypoglycemia. ${ }^{[3]}$ Hence, the possibility of sepsis with an underlying CKD resulting in hypoglycemia is entertained in this case. Insulinoma presenting for the $1^{\text {st }}$ time and accidental/suicidal ingestion of long-acting oral hypoglycemic agent (e.g., glibenclamide) are other possibilities, but a raised TLC do not favor these diagnoses.

It is probable that an underlying CKD remained undetected in this case. While it is now common practice to do GT'T to detect gestational diabetes between 24 and 28 weeks of pregnancy, there is no record to show if serum creatinine was done in this case as part of AN checkup. This case underlines the importance of doing serum creatinine in addition to hemoglobin $\%$, blood sugar/GTT and urine albumin/sugar as part of routine antenatal (AN) work up even in small health centers.

\section{Acknowledgement}

- The details of the case were noted from the archives of the Medical Records Department of RGGGH, Chennai-600 003.

- The author thanks the Head of Department and Professor of Nephrology, MMC and RGGGH for providing me with valuable insight into the possibilities in this case.

- The author thanks the Director, as well as other Professors in the Institute of Internal Medicine, MMC and RGGGH, who supported the idea of sending this case for publication.

\section{Financial support and sponsorship}

Nil.

\section{Conflicts of interest}

There are no conflicts of interest

\section{REFERENCES}

1. Rabkin R, Ryan MP, Duckworth WC. The renal metabolism of insulin. Diabetologia 1984;27:351-7.

2. Moen MF, Zhan M, Hsu VD, Walker LD, Einhorn LM, Seliger SL, et al. Frequency of hypoglycemia and its significance in chronic kidney disease. Clin J Am Soc Nephrol 2009;4:1121-7.

3. Miller SI, Wallace RJ Jr, Musher DM, Septimus EJ, Kohl S, Baughn RE Hypoglycemia as a manifestation of sepsis. Am J Med 1980;68:649-54. 